\title{
Exploration on the cultivation of Computational Thinking Ability in the teaching of PhotoShop
}

\author{
Tingting Pan, Guohua Zhan, Zhihua Li \\ Hangzhou Institute of Service Engineering \\ Hangzhou Normal University \\ Hangzhou, China \\ ptt15896044470@163.com,ghzhan@hznu.edu.cn,zhihuali_e@163.com
}

\begin{abstract}
Considering the present situation of PhotoShop teaching in Colleges and universities, most attention is paid on the imparting knowledge and skills, but the refined thinking is ignored. In this paper, a new method is introduced by cultivating students' computational thinking in the Heuristic teaching based on mind mapping and driving teaching. This method sums up the significance of the computational thinking in the teaching of PhotoShop in Colleges and Universities. The experimental results show the method can help students cultivate the ability of computational thinking, so as to achive the aim of innovation on PhotoShop usage.
\end{abstract}

Keywords-Computational thinking; Mind mapping; Heuristic teaching; Task-driven teaching

\section{INTRODUCTION OF COMPUTATIONAL THINKING}

In March 2006, Jeannette Wing, a professor of computer science at the University of America Carnegie Mellon University, proposed the "Computational Thinking" concept in the journal of the American computer authority Communications of the ACM and made a detail definition. It pointed out "Computational Thinking is a fundamental skill for everyone, not just for computer scientists; Computational thinking involves solving problem, designing system, and understanding human behavior, by drawing on the concepts fundamental to computer science; Computational thinking is reformulating a difficult problem into one we know to solve, perhaps by reduction, embedding, transformation, or simulation; It is using heuristic reasoning to discover a solution; Computational thinking is not programming, it requires us thinking at multiple levels of abstraction ${ }^{[1]}$; The aim is to hope that all people can think like a computer scientist, so as to find the solution of the problem, and realize the innovation." Immediately, this theory has been widely discussed and studied by many scholars both at home and abroad, some computer educators in teaching processes also gradually emphasis on computational thinking ability.

In 2008, the CSTA in United States released a report online named Coputational Thinking: A problem solving tool for every classroom which supported by Microsoft, it summaraized what is Computational thinking ${ }^{[2]}$. In July 2010, Xi'an JiaoTong University held the first "nine school alliance (C9) computer fundamental curriculum seminar", the seminar discussed how to improve the quality of computer basic teaching in the new situation, afterwards, published a statement Nine schools league (C9) computer basis teaching development strategy a joint statement, And will computational thinking as the core task to build a more perfect basic computer teaching system $^{[3]}$.

A large number of studies show that the computational thinking is adapted to the needs of the times, is met the needs of the information society Innovation, Scientific studies are needed the correct guidance of computational thinking, to cultivate the innovative talents that the society need, the scholars can use efficient thinking to think, also need to have a scientific thinking to guide to jump out of the traditional teaching mode.

\section{PHOTOSHOP}

\section{A. Introduction of PhotoShop}

PhotoSHop is a famous and most popular image processing and making software, It is strong in practice and operation, rich in content, wide in use, with graphic making, advertising designing, photography processing, image creating, web producing, late modifying, packaging devising, interface designing, multimedia making etc. Also, with the popularization of network and electronic products, PhotoShop has been involved in all walks of life, such as television, film, animation, photography, advertising, art, games, military and so on. Nowadays, it has become a compulsory course in college multimedia courses.

\section{B. Status of teaching in PhotoShop}

In the daily teaching process, the teacher's teaching of PhotoShop is confined to books, students can only learn limited knowledge from books. Firstly, with the rapid development of the Internet, the demand for the PhotoShop of the market is getting higher and higher, not only need to have a superb technical level, but also has a unique ability to innovate; then, with the rapid updating of PhotoShop software, the knowledge we have learned from school seems to can't keep up with times.

The traditional PhotoShop teaching only teaches students to master the basic operation of books, so that students can be independent of some basic processing on images, such as matting, synthesis, adjustment etc. But this is far from enough, and even can say that we can't get out of school. At present, the shortcomings of PhotoShop teaching mainly reflected in the following aspects:

1) The curriculum of teacher spoken dull as ditch water, students have little interest

PhotoShop has a quite powerful image processing 
function, correspondingly, there are a lot of knowledge. The teacher must explain these knowledge, but lack of vivid class model, makes students feel reluctant to learn because the felling of boring.

2) Teaching pays attention on imparting knowledge and skills, ignoring refining thinking

At present classes, Teachers mainly adopt the method of direct interpretation of the book knowledge and case, and ignore the thinking in the process of transmission of knowledge. While the students begin to operate, most of them will mechanically imitate the teacher's case, So as to make students lose the ability of active thinking and dependent on the teachers extremely. Even after the completion of homework, is not active, just to complete a task to complete a burden, more students are taught to copy other students' homework. If things go on like this, they cannot solve problems even have no way to start when in face of the complex situations.

3) Students lack of innovation ability

The teaching of PhotoShop is mainly used in the following ways: in class, students listen to the teachers to explain in details the use of the commands, tools, case steps, and after class operation examples on computers; examinations by way of a combination of written and operation on computers etc. These methods are very effective, but there is disadvantage that cannot fully investigate the students' practical ability. Students tend to meet the tests by direct recite and fast memory, if things continue this way, due to lack of imagination and thinking, it is hard to cultivate talents which social required ${ }^{[4]}$.

\section{COMBINING WITH COMPUTATIONAL THINKING TO LEARN PHOTOSHOP}

When teaching PhotoShop, We need to avoid the "heavy operation, light thinking"[5], we should not simply go to learn the usage and the effects of each tool when learning PhotoShop software, what we must learn is how to deal with the images or design images. So as to be more flexible and easy to use PhotoShop to solve real life problems, and thus will not be eliminated by the rapid development of the times.

According to the characteristics of PhotoShop course and the understanding of the training of Computational Thinking, teachers can adopts the way which combines Heuristic teaching based on mind mapping with driving teaching to give instruction. The aim is to cultivate students' thinking ability and develop students' thinking mode.

\section{A. The heuristic teaching based on the mind mapping}

Mind mapping, which is proposed by famous psychologist, education expert Tony Buzan in 1960s, is a thinking structure that diffuse knowledge from the center to the surrounding knowledge ${ }^{[6]}$, follows a set of rules that are simple, basic, natural and easy to be accepted by the brain. It probably means that, start from a center or an important point of knowledge, the other sub knowledge points are derived recursively until all knowledge points are expressed. The whole mind mapping is composed of lines, graphics, colors, words, symbols and other elements, is expressed by tree structure, shows a thinking process, which helps to divergent thinking ${ }^{[7]}$. In short, mind mapping is a scientific and efficient way of thinking, can continue to inspire people's potential, improve people's memory and creativity, to help people in the study, work, creative inspiration and find methods, so many fields are applied.

Heuristic teaching is a kind of teaching method which is based on the content that the teacher teaches, and has the purpose to guide students to think, to excavate the potential of the students as well as to improve their quality. Instead of most of the colleges' and universities' boring injection type teaching style, it is not a mechanical teaching mode, but a teaching mode of thinking, the whole teaching activity is consist of Students' main body activity as the main line and teachers' guidance as the subordinate line. In short, heuristic teaching pays more attention to communicate with students and inspire students to think, in addition, help students learn knowledge also develop their thinking ability.

Hence, this section we fuse the mind mapping and the heuristic teaching and put forward the thinking way of increasing the mind mapping in the heuristic teaching method to study PhotoShop. For example, when teaching PhotoShop, teachers can use mind mapping to present the knowledge of this lesson in the form of a tree, highlight the value of information. This way can facilitate students to clarify ideas and know what will be learned, rather than blindly cramming to memorize. When teachers talk about the knowledge of a specific point, can use it again to do a more detail knowledge of the tree. So in such a way to teach, and students can be clear, the situation that the teacher speaks the most, but the students don't know what the teacher was saying will not appear. At the same time, teachers should encourage students to think when teaching. They can ask students questions through some examples, and encourage students to take the initiative to ask questions, and then through the development of the students' thinking and inspiration to guide students to solve their problems on their own, improve their ability to solve problems and analyze problems, encourage them to seek the optimal solution. Let students learn in the classroom of PhotoShop knowledge transform into practical problem-solving skills ${ }^{[9]}$.

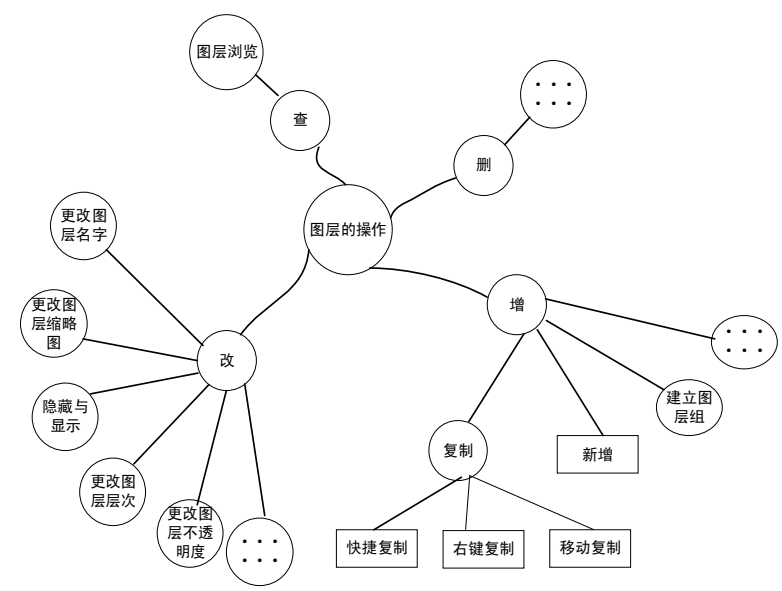

Fig.1 Take the operation of the layers as an example to construct the mind mapping 
When teaching the operations of layers, teachers can through the crud of layers to draw out various operations, as shown in Figure 1 above. At the same time, teachers can inspire the students to imagine the layers as glass, When all kinds of operations on the layer, it can be imagined as painting on the glass, each time add a layer of layers, it is conceivable that spread into a layer of glass. Heuristic teaching based on mind mapping is believed to be helpful in teaching and learning.

\section{B. The task-driven teaching}

Task-driven teaching is that teachers implicit knowledge in one or more specific tasks, so that students through the tasks of cognition, understanding, thinking and application, to complete a specific task as well as to achieve the teaching objectives. In view of the knowledge that they learned in class is easy to forget, the task-driven teaching can help students to master knowledge, clear the content of the learned. On the other hand, the students' consciousness is generally not high, task-driven teaching method ask for students take the tasks to learn, so that the students have a kind of motivation and sense of urgency to complete the task, as a result, can promote the students' efforts to complete the knowledge that must learned in a limited time. Its core purpose is to allow students to learn how to learn, how to solve the problems when encountered, so that transfer and use the knowledge ${ }^{[9]}$.

When starting the class, teachers can raise a total task based on semester and subtasks based on each lesson. The general task is constructed based on all knowledge points of PhotoShop, the subtasks are designed based on the knowledge points of each lesson. We do not have the standard answer to each task, and we all depend on each student's imagination. If encounter problems when completing the tasks, teachers can inspire students to think and learn by using computational thinking, so that students can use the high efficiency of Computational thinking to solve practical problems and explore new knowledge.
In short, the task-driven teaching method has fully played the students' ability and creativity in the process of learning, so that students via the specific operation of the book on the empty theory to a live application.

\section{THE SIGNIFICANCE}

In PhotoShop courses, training students' ability of computational thinking can subtly to make students understand and solve problems by scientific computational thinking. To cultivate students' innovation ability and improve students' overall quality is a development of traditional teaching method. It is also a good teaching method of PhotoShop teaching in Colleges and universities.

[1] Jeannette M. Wing, "Computational Thinking [J]" in Communication of the ACM, pp. 33-35, March 2006.

[2] Qin Mo, Liang Tan, "Research and progress of Computational Thinking" in Computer Science, pp.10-15, March 2011.

[3] Qinming He, Hanquan Lu, Boqin feng, "The core of computer basic teaching task is to calculate the cultivation of thinking ability"in China University Teaching, pp.5-9, September 2010.

[4] Xinyu Zou, "Theory of PhotoShop teaching in mechanic college present situation and innovation" in Education, pp. 210-211, December 2014

[5] Jianpu Guo, Lixin Liu, Xiaoxiao Dong, "Training of Computational-thinking ability in Multimedia Course" in Computer Education, pp.54-59, June 2013.

[6] Shubo Li, "Research on the application of mind mapping in PhotoShop Teaching" in China Education Innovation, pp.174, 2012.

[7] Jun Cao," The application of mind mapping as a teaching tool -- a case study of Photoshop software",pp.165-166, March 2009

[8] HongGang, "A preliminary study on the teaching reform of computer information technology based on the training of Computational Thinking Ability" in university education, pp. 156158, December 2015

[9] Ruyun Zhang, Boyong Xu,"The application of "task driven" teaching method in Higher Vocational PhotoShop Teaching" in Education science, pp.56-57, March 1989. 